\title{
Telhado verde: desempenho do sistema construtivo na redução do escoamento superficial
}

\author{
Green roof: performance of the constructive system in \\ the reduction of runoff
}

\section{Pedro Tyaquiçã da Silva Santos \\ Sylvana Melo dos Santos \\ Suzana Maria Gico Lima Montenegro \\ Artur Paiva Coutinho \\ Glawbber Spíndola Saraiva de Moura \\ Antônio Celso Dantas Antonino}

Pedro Tyaquiçã da Silva Santos Departamento de Engenharia Civil, Centro de Tecnologia e Geociências Universidade Federal de Pernambuco Avenida Acadêmico Hélio Ramos, $\mathrm{s} / \mathrm{n}$, Cidade Universitária Recife - PE - Brasil CEP 50741-530

Tel.: (81) 2126-8201

E-mail: tyaquica@gmail.com

Sylvana Melo dos Santos Núcleo de Tecnologia, Centro Acadêmico do Agreste

Universidade Federal de Pernambuco Rodovia BR-104, km 59, s/n, Sítio Juriti, Zona Rural Caruaru - PE - Brasil CEP 55002-970 Tel.: (81) 2126-7774

E-mail: sylvana.ufpe@gmail.com

Suzana Maria Gico Lima Montenegro Departamento de Engenharia Civil, Centro de Tecnologia e Geociências Universidade Federal de Pernambuco

E-mail: suzanam@ufpe.br

Artur Paiva Coutinho Departamento de Engenharia Civil, Centro de Tecnologia e Geociências Universidade Federal de Pernambuco E-mail: arthur.coutinho@hotmail.com

Glawbber Spíndola Saraiva de Moura

Departamento de Engenharia Civil, Centro de Tecnologia e Geociências Universidade Federal de Pernambuco

E-mail: glawbber@yahoo.com.br

Antônio Celso Dantas Antonino Departamento de Energia Nuclear, Centro de Tecnologia e Geociências Tel.: (81) 2126-7973

E-mail: acda@ufpe.br

Recebido em 03/10/12 Aceito em 02/03/13

\section{Resumo}

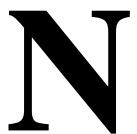

a atualidade, metade da população mundial reside em centros urbanos, e os impactos negativos decorrentes de eventos hidrológicos têm sido recorrentes, visto que, com o aumento da impermeabilização, há redução nas taxas de infiltração, levando à diminuição da recarga dos aquíferos e à diminuição do escoamento de base. Consequentemente, o escoamento superficial é intensificado, aumentando a frequência e a magnitude dos picos de cheia, o que pode resultar na ocorrência de inundações, especialmente nos centros urbanos. Por outro lado, verifica-se já há algum tempo o emprego de telhados verdes em várias partes do mundo para contribuição arquitetônica estética e melhoria do conforto ambiental. Além desses enfoques, esta solução vem sendo tratada, também, como uma estrutura de controle do escoamento pluvial. Considerando características reais e os dados obtidos em campo, foi realizada a simulação da dinâmica da água em dois telhados verdes, com o emprego do código computacional Hydrus-1D, para diferentes intensidades de precipitação, visando verificar o desempenho desse sistema construtivo na redução do escoamento superficial. Os hidrogramas de saída mostraram-se qualitativamente adequados e quantitativamente coerentes e pode-se concluir que os telhados verdes constituem importantes dispositivos no amortecimento do escoamento superficial oriundo dos telhados, para as condições climáticas da área investigada.

Palavras-chave: Construção sustentável. Água de chuva. Hydrus-1D. Drenagem urbana.

\section{Abstract}

Nowadays, half of the world's population lives in urban areas, and the negative impacts of hydrological events have been recurrent due to growing urbanization, impervious soil coverage, and the consequent reduction in infiltration rates leading to decreasing aquifer recharge and surface runoff. Thus, runoff increases, intensifying peak flows and flood events. By contrast, green roofs have been applied for some time in several parts of the world both for architectural-aesthetic reasons and to improve environmental comfort. Moreover, they are also being used in view of their performance as an urban runoff control device. Considering actual characteristics and field data, an experiment was performed in order to investigate the water dynamics in two green roof systems. The Hydrus- $1 D$ unsaturated flow numerical model was used to process the data, considering different rainfall rates. The analyses of the hydrograms produced consistent qualitative and quantitative results, and it was possible to conclude that, for the climate conditions of the area investigated, green roofs are important devices to be used in the reduction of runoff from traditional roofs.

Keywords: Eco house. Rainfall. Hydrus-1D. Urban drainage. 


\section{Introdução}

O crescimento populacional, o aumento das construções e a mudança radical da paisagem têm caracterizado o processo de urbanização nas últimas décadas. Em 1950, um terço da população mundial residia em cidades (UNITED NATIONS, 2005) e, de acordo com as informações do IBGE (INSTITUTO..., 2010), já se verifica no Brasil um contingente maior que $85 \%$ da população residindo nas áreas urbanas.

Nesse crescente cenário de urbanização, impactos ambientais e socioeconômicos decorrentes de eventos hidrológicos têm sido recorrentes e têm demandado a busca por soluções que não se limitam à aplicação de técnicas tradicionais. Hidrologicamente o problema se caracteriza pela redução da infiltração da água pluvial no solo devido ao aumento de áreas impermeabilizadas. Consequentemente ocorre diminuição das taxas de recarga para os aquíferos e diminuição do escoamento de base. O escoamento superficial é, então, intensificado, resultando no aumento da frequência e da magnitude dos picos do hidrograma de escoamento, levando à ocorrência de enchentes e frequentemente de inundações, tendo sido considerado neste trabalho que a enchente está associada à ocorrência natural, que corresponde à elevação do nível d'água além dos limites normais do escoamento natural, e que a inundação normalmente decorre de modificações no uso do solo e provocam o extravasamento da água para além dos níveis máximos do curso d'água.

Nesse contexto, a aplicação de técnicas que minimizem o escoamento superficial, como os telhados verdes, sobre a tradicional malha de drenagem urbana é bem-vinda. Ao pesquisar possíveis variações dessa tecnologia nos últimos 10 anos, Dunnet e Kingsbury (2004) encontraram duas abordagens: os telhados verdes extensivos e os telhados verdes intensivos. Segundo Santos et al. (2009), os telhados verdes extensivos têm a concepção inerente de ser quase "autossustentáveis", ou seja, de necessitar de apenas um mínimo de manutenção, como, por exemplo, irrigações esporádicas e pouco uso de fertilizantes; por outro lado, os telhados que requerem uma razoável profundidade de solo, devido ao grande crescimento das plantas, são chamados de intensivos, devido ao "intensivo" trabalho de manutenção que demandam, como irrigação e fertilizantes, envolvendo, portanto, maior custo de implantação e manutenção (DUNNETT; KINGSBURY, 2004; PECK, 1999).

Pelas diversas contribuições que vêm apresentando, os telhados verdes têm sido estudados sob o enfoque dos detalhes construtivos, da mudança comportamental, da inserção nos meios urbanos e rurais, e do desempenho como estrutura de controle do escoamento pluvial, entre outros. Getter e Rowe (2006) apresentaram uma revisão relacionada aos benefícios do emprego dos telhados verdes, em que destacaram redução no volume e retardo do escoamento superficial, aumento da vida útil do telhado, conservação de energia, aumento da biodiversidade, mitigação da poluição do ar, valor estético, entre outros.

VanWoert et al. (2005) realizaram dois estudos com vários tipos de telhados para quantificar os efeitos na retenção da água de chuva. No primeiro estudo foram utilizados três diferentes telhados: um telhado convencional com pedregulho, um verde extensivo sem vegetação e um verde extensivo com vegetação. Segundo os autores, o percentual médio de retenção da água de chuva variou de $48,7 \%$ (pedregulho) a $82,8 \%$ (telhado vegetado). No segundo estudo foi investigada a influência da inclinação do telhado (2\% e 6,5\%) e a influência da profundidade média do telhado verde $(2,5,4,0$ e $6,0 \mathrm{~cm})$. Para todos os eventos de chuva, as plataformas com inclinação de $2 \%$ com uma espessura média de $4 \mathrm{~cm}$ tiveram a maior retenção média de $87 \%$, sendo a diferença das outras formas de tratamento mínima. Os autores afirmaram que a combinação de inclinação e espessuras médias reduzidas diminui a quantidade total de escoamento superficial. Em ambos os estudos, os telhados verdes não apenas reduziram o volume de água escoado como também estenderam esse comportamento para o período após o evento chuvoso. Nesse contexto, os autores detectaram que o registro do escoamento superficial se encerrou, no primeiro experimento, após $3 \mathrm{~h}$ de concluído o evento de chuva e, no segundo experimento, se encerrou $30 \mathrm{~min}$ antes do primeiro.

Burszta-Adamiak (2012) realizou, em um prédio da Universidade de Ciências da Vida e Meio Ambiente em Wrocław, na Polônia, ensaios para determinação da capacidade de retenção dos telhados verdes, do retardo no escoamento superficial e da redução no pico do hidrograma durante eventos de chuva. Os telhados verdes com várias camadas contribuíram para a redução da velocidade do escoamento e a redução no pico do hidrograma em comparação ao valor máximo de precipitação registrado. De acordo com o autor, a retenção média para 153 eventos de precipitação analisados variou de $82,5 \%$ a $85,7 \%$ para os telhados verdes e, no caso de eventos até 1

162 Santos, P. T. da S.; Santos, S. M. dos; Montenegro, S. M. G. L.; Coutinho, A. P.; Moura, G. S. S. de; Antonino, A. C. D. 
$\mathrm{mm} /$ dia, a retenção dessas estruturas atingiu aproximadamente $100 \%$.

Mentes, Raes e Hermy (2006) analisaram medições registradas em 18 publicações e observaram a existência de relações entre precipitação e escoamento em escala de tempo anual e sazonal a partir de 628 dados disponíveis e o emprego de modelos empíricos. Segundo os autores, a relação anual entre precipitação e escoamento superficial para telhados verdes é fortemente determinada pela profundidade da camada de substrato, e a retenção da água de chuva nos telhados verdes, em volume, é menor, em termos percentuais, no inverno que no verão. Os autores associaram essa diferença de comportamento à distribuição da evapotranspiração e da precipitação. Analisando-se os dados de precipitação em escala anual, para a região de Bruxelas, observou-se que, com a aplicação de telhados verdes extensivos, em apenas $10 \%$ das edificações existentes, houve uma redução de $2,7 \%$ do escoamento superficial, considerando toda a região estudada. Os autores destacaram que os telhados verdes podem ser muito úteis na redução do escoamento resultante dos eventos de precipitação.

Palla et al. (2008) estudaram o desempenho dos telhados verdes usando o software EPA SWMM para modelar os efeitos hidrológicos de três cenários de telhados verdes hipotéticos.

O modelo foi calibrado e validado com dados de um pequeno telhado verde implantado na Universidade de Genova, na Itália. Os cenários de precipitação foram estabelecidos com base em 18 anos de dados de pluviômetros de alta resolução (1 min). De acordo com os autores, a modelagem hidrológica demonstrou que a implementação de telhados verdes em uma grande área pode reduzir significativamente o pico do escoamento superficial e o tempo de retardo (7 e $15 \mathrm{~min}$ ) do volume escoado (efeito detenção), enquanto, após a introdução de um processo de secagem relacionado com a evapotranspiração, durante o período entre eventos, pode-se observar a redução do volume do escoamento superficial (efeito retenção).

Carter e Rasmussen (2006) monitoraram por um ano um telhado verde construído na Universidade da Georgia para investigação da efetividade dos telhados verdes na redução do escoamento da água de chuva. Os 31 eventos de precipitação monitorados variaram de $0,28 \mathrm{~mm}$ a $8,43 \mathrm{~mm}$. Os autores observaram que a retenção da precipitação pelo telhado verde diminuiu com o aumento da precipitação: de até $90 \%$ para precipitações pequenas $(<25,4 \mathrm{~mm})$ para menos que $50 \%$ para precipitações grandes (> 76,2 mm). Além disso, os autores destacaram o atraso no escoamento superficial, de $17,0 \mathrm{~min}$ para o telhado convencional e de 34,9 min para o telhado verde, observando-se um aumento médio de 17,9 min.

Diante do exposto, o principal objetivo deste trabalho é analisar o desempenho de dois telhados verdes utilizando-se o modelo Hydrus. Em um deles foi utilizada como cobertura uma vegetação gramínea, e no outro, uma vegetação cactácea, sob o enfoque da capacidade de retenção do escoamento superficial.

\section{Material e métodos}

\section{Descrição da área de estudo}

Esta pesquisa se desenvolveu no estado de Pernambuco, no município de Caruaru, que apresenta um clima quente e de chuvas escassas, características de regiões semiáridas. Considerando a caracterização apresentada por Horner e Jens (1942), em que as chuvas podem ser agrupadas em padrões avançados, intermediários e atrasados, quando o pico de maior intensidade da chuva ocorre, respectivamente, no primeiro terço, no segundo terço e no terceiro terço do período de duração total da chuva, Santos e Montenegro (2012) identificaram que, na região onde se realizou esta pesquisa, Agreste Central pernambucano, no padrão avançado, $50 \%$ dos valores são maiores que $38 \mathrm{~mm} \mathrm{~h}^{-1}$, chegando a valores de até $300 \mathrm{~mm} \mathrm{~h}^{-1}$, o que corresponde a uma lâmina de $10 \mathrm{~mm}$ em $2 \mathrm{~min}$. Segundo os autores, chuvas de alta intensidade são bem características dessa região, e aproximadamente $30 \%$ das intensidades de precipitação, do padrão avançado, são valores superiores a $60 \mathrm{~mm} \mathrm{~h}^{-1}$. Em totais anuais, as precipitações dessa região apresentam um padrão de grande variabilidade no decorrer dos meses, ocorrendo de forma irregular, e a precipitação acumulada para o município de Caruaru é de $500 \mathrm{~mm}$ a $600 \mathrm{~mm}$. Nessa região verifica-se que a taxa de evapotranspiração potencial é superior aos valores de precipitação durante todo o ano, sendo mais críticos os meses de agosto a dezembro.

Os telhados verdes utilizados nesta pesquisa foram implantados por Santos et al. (2009) em uma das edificações térreas preexistentes da estação experimental do Instituto Agronômico de Pernambuco, que possui três ambientes semelhantes, aproximadamente $4 \mathrm{~m}^{2}$ cada, que foram utilizados para a instalação de dois telhados verdes (Figura 1).

Conforme descrito por Santos et al. (2009), após a retirada das telhas cerâmicas e a realização de 
pequenas adaptações (colocação de muretas delimitadoras dos ambientes com $45 \mathrm{~cm}$ de altura, impermeabilização e instalação de dutos para armazenamento da água escoada), foram implantadas as vegetações. Os autores destacaram a necessidade de um telhado de referência e, para isso, destinaram um terceiro ambiente, de área aproximadamente igual às duas utilizadas para funcionar como telhado de controle. Mantiveramse assim as telhas cerâmicas e, além da mureta delimitadora lateral, da mesma altura que as construídas nos telhados verdes, foram instalados a calha e os dutos para escoamento da água precipitada até os tonéis de armazenamento, com capacidade de 240 L (um para cada área delimitada). As espécies vegetais plantadas nos telhados verdes foram Melocactus macrodiscus, que é uma cactácea popularmente conhecida como coroa-de-frade (Figura 2a), encontrada facilmente na região de estudo, e Cynodium dactylum, que é uma gramínea muito empregada em jardins, mais conhecida como grama-de-burro (Figura 2b). Os autores afirmaram ainda que as espécies plantadas foram selecionadas considerando-se, principalmente, sua capacidade de sobrevivência diante da baixa disponibilidade hídrica da região.

\section{Descrição do experimento}

O experimento realizado consistiu em "precipitar" sobre o telhado determinada quantidade de água com intensidade controlada e na realização de registro de umidade do solo e do nível d'água nos tonéis de armazenamento simultaneamente. A precipitação foi aplicada com o emprego de um simulador de chuva, que foi construído utilizandose tubulação rosqueável de 1/2", aspersores de irrigação, manômetro de pressão hidráulica e bomba centrífuga de $1 / 2 \mathrm{CV}$.

O experimento foi realizado nos dias 2, 21 (experimento 1) e 28 (experimento 2) de janeiro de 2011. No dia 21 de janeiro a precipitação acumulada até a data foi de $17,25 \mathrm{~mm}$, tendo sido observada nesta data uma precipitação de $1,8 \mathrm{~mm}$ após um período de mais de 5 dias sem precipitação. Entre os dias 21 e 28 de janeiro verificou-se a ocorrência de precipitação diária que variou de $0,3 \mathrm{~mm}$ a $37,8 \mathrm{~mm}$, e no dia do experimento não houve precipitação. No experimento 1 a intensidade "precipitada" sobre a estrutura foi de $42 \mathrm{~mm} / \mathrm{h}$, e no experimento 2 foi de $79 \mathrm{~mm} / \mathrm{h}$, tendo sido adotados $30 \mathrm{~min}$ como o tempo de duração de cada "precipitação".

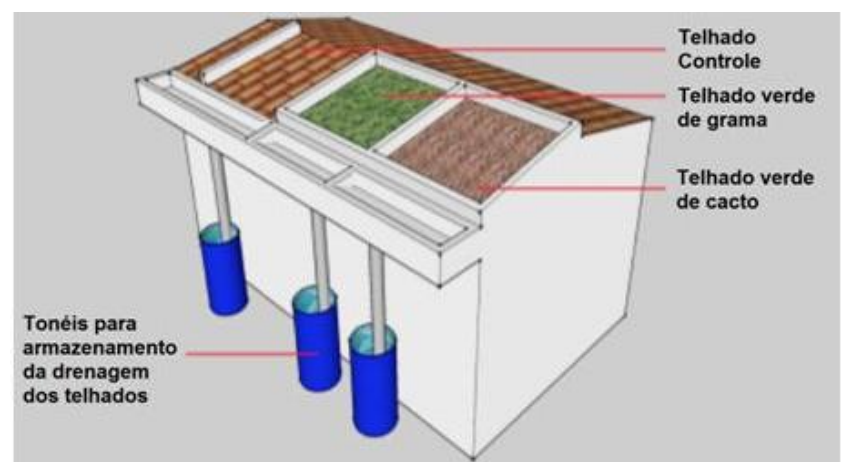

Figura 1 - Esquema com a disposição dos telhados verdes e convencional instalados no IPA

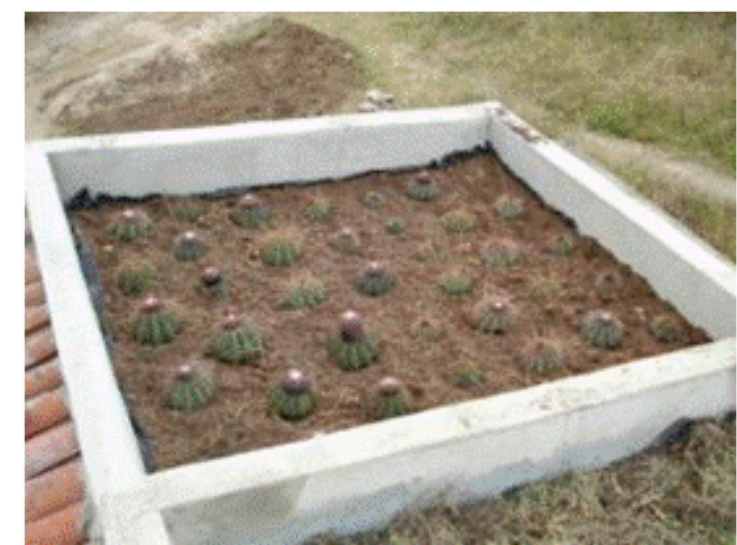

(a) Melocactus macrodiscus (coroa-de-frade)

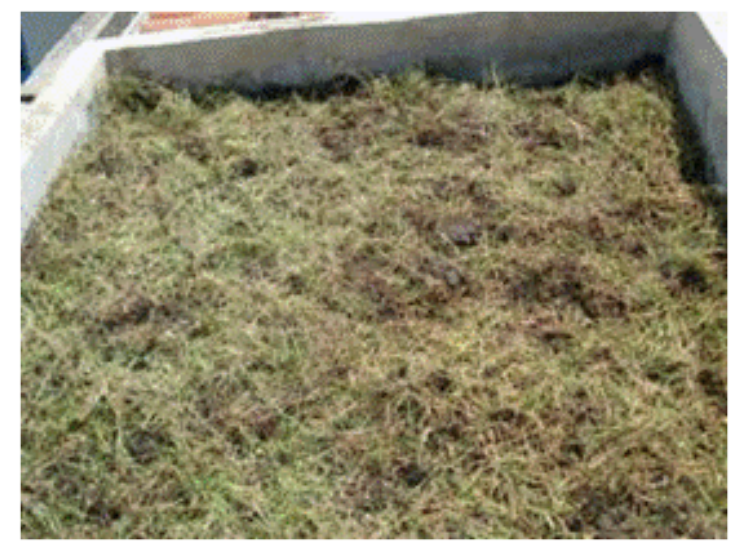

(b) Cynodium dactylum (grama-de-burro)

Figura 2 - Vegetações utilizadas nos telhados verdes implantados no IPA (Caruaru, PE)

164 Santos, P. T. da S.; Santos, S. M. dos; Montenegro, S. M. G. L.; Coutinho, A. P.; Moura, G. S. S. de; Antonino, A. C. D. 
Na determinação dos volumes "precipitados" foram considerados os respectivos tempos de retorno $(\mathrm{Tr})$, que correspondem ao número médio de anos no qual se espera que determinado evento (precipitação ou vazão) seja igualado ou superado. Frequentemente $\mathrm{o} \operatorname{Tr}$ da precipitação não corresponde ao mesmo da vazão gerada pelo respectivo evento chuvoso, e isso ocorre devido a vários fatores: tipo e cobertura de solo, condições iniciais de umidade do solo, distribuição temporal e espacial da precipitação, entre outros.

$\mathrm{O}$ valor de $\operatorname{Tr}$ pode ser determinado pela análise estatística das relações entre as variáveis observadas em eventos extremos, empregando-se séries hidrológicas existentes representativas do local analisado, que resultam nas equações IDF (intensidade, duração e frequência). Sendo assim, empregou-se, no âmbito desta pesquisa, a relação apresentada por Coutinho et al. (2010) para o município de Caruaru (Equação 1). Neste contexto, considerando-se as intensidades de $42 \mathrm{~mm} / \mathrm{h}$ e 79 $\mathrm{mm} / \mathrm{h}$ na Equação 1 chega-se, respectivamente, aos Tr de 3 e 57 anos.

$I=\frac{228,02 \cdot \operatorname{Tr}^{0,229}}{(t+2,830777)^{0,558067}}$

Eq. 1

Sendo:

I, a intensidade da precipitação [L/T], comumente expressa por $(\mathrm{mm} / \mathrm{h})$;

Tr, o tempo de retorno, [T], em anos; e

t, a duração do evento, [T], em minutos.

\section{Equipamentos instalados}

Para a obtenção dos valores de umidade do solo e do nível d'água nos tonéis de armazenamento, foram instaladas duas sondas TDR (Time-Domain Reflectometry) e dois sensores de nível d'água. Além destes, para ratificação do volume precipitado, foi instalado um pluviômetro de báscula.

Os sensores TDR utilizados são do modelo EC-5 da Decagon Devices Inc., e foram instalados verticalmente no solo dos telhados verdes, a uma profundidade de $3 \mathrm{~cm}$, que corresponde ao perfil total do substrato dos telhados, para a obtenção dos valores de umidade do solo. Esses dados foram empregados como parte das condições iniciais do solo para simulação do modelo numérico no código computacional Hydrus-1D.

Os sensores de nível instalados são do modelo Levelogger 3001, da empresa Solinst Inc., e possuem corpo selado em aço inoxidável 316, datalogger interno para leitura, em intervalos predefinidos (no caso, cada minuto), e armazenamento dos dados. Os referidos sensores foram empregados na medição do nível da água armazenada no interior dos tonéis que acumulam a água escoada dos telhados, visando comparar os volumes recolhidos de cada sistema construtivo.

O pluviômetro empregado nos experimentos é do modelo Rain Gauge, da marca Hobo, permite a medição de precipitação igual ou superior a 0,2 $\mathrm{mm}$ e foi instalado no centro da área de $12 \mathrm{~m}^{2}$ para a determinação da lâmina de água precipitada. Além do pluviômetro, seis beckers foram dispostos sobre os telhados, e a quantidade de água total contida nos mesmos, ao final de cada experimento, foi medida, possibilitando assim a correlação total da medição realizada pelo pluviômetro.

Todos os dados coletados dos equipamentos citados foram armazenados em um datalogger modelo Hobo Mini Station em intervalos de tempo sincronizados, o qual foi instalado em um cômodo fechado, destinado a depósito, sem acesso de estranhos, no ambiente logo abaixo do telhado verde de cactos.

\section{Determinação dos parâmetros do solo}

Os modelos matemáticos que simulam o movimento da água nos solos, de modo geral, exigem o conhecimento de um grande número de informações, o que normalmente implica a necessidade de realização de ensaios de campo e de laboratório. Como a realização desses ensaios geralmente são onerosos e, muitas vezes, demorados, o uso de métodos indiretos (que se baseiam em dados disponíveis, usuais e de baixo custo) constitui um importante recurso para a determinação de alguns parâmetros de solo. Nesse contexto, teorias e modelos matemáticos têm sido desenvolvidos para descrever com propriedade o movimento da água no solo (HAVERKAMP et al., $1998^{1}$ apud SOUZA et al., 2008).

Souza et al. (2008) apresentaram o método semifísico "Beerkan", no qual a estimativa dos parâmetros da curva característica da umidade do solo ou curva de retenção da água no solo relaciona o potencial matricial (h) e a umidade volumétrica do solo $\theta(\mathrm{h})$, e a dos parâmetros da curva de condutividade hidráulica relaciona a condutividade hidráulica $K(\theta)$ e a umidade volumétrica. Segundo os autores, nesse método, essas curvas podem ser descritas, analiticamente, por cinco parâmetros: dois de forma, $m$ ou $n$ e $\eta$, relacionados principalmente com a textura, e três de normalização $\theta_{\mathrm{s}}$ (umidade volumétrica

\footnotetext{
${ }^{1}$ HAVERKAMP, R. et al. Scaling of the Richards Equation and its Application to Watershed Modeling. In: SPOSITO, G. (Ed.). Scale Dependence and Scale Invariance in Hydrology. Cambridge: Cambridge University Press, 1998. p. 190-223.
} 
saturada), Ks (condutividade hidráulica saturada) e hg (valor de escala do potencial matricial), dependentes da estrutura do solo. Os parâmetros de forma citados são obtidos a partir da curva de distribuição dos tamanhos das partículas, enquanto os parâmetros de normalização são determinados a partir de experimentos de infiltração.

Os ensaios de infiltração realizados consistiram na determinação do tempo que volumes de água (70 $\mathrm{mL})$, inseridos de forma contínua em infiltrômetros de anel simples, levaram para ser infiltrados. Em cada teste foram coletadas amostras de solo para a determinação da massa específica dele, umidades inicial $\left(\theta_{\mathrm{o}}\right)$ e final $\left(\theta_{\mathrm{s}}\right)$ (Tabela 1).

A caracterização granulométrica dos solos foi realizada nas instalações do Laboratório de Física do Solo do Departamento de Energia Nuclear da UFPE, e a metodologia adotada obedeceu à sequência de procedimentos de ensaios normalizados que visam determinar a distribuição granulométrica dos solos, apresentada na NBR 7181 - Solo - Análise Granulométrica, da ABNT (ABNT, 1984). Na Tabela 2 estão apresentadas as frações granulométricas dos solos dos telhados verdes, assim como a porcentagem de matéria orgânica e densidade das partículas ( $\rho)$ dos mesmos.
Os fatores determinantes no desempenho dessas estruturas são as características da vegetação (morfologia e idade) e as características do substrato (espessura e composição). As características da vegetação, morfologia e idade, são particularmente responsáveis pelo retardo no escoamento devido à interceptação da água pela folhagem existente, ou seja, efeito retenção. O solo dos telhados vegetados apresenta uma fração considerável de areia (Tabela 2), proporcionando ao substrato maior porosidade em seu perfil, o que influi diretamente no tempo necessário para que o solo atinja o estado de saturação (REICHARDT, 1990).

\section{Modelagem matemática: dados de entrada e condições de contorno e iniciais}

Os dados de entrada utilizados pelo programa Hydrus-1D para simulação da dinâmica da água no solo são: tempo da simulação, dimensões da área analisada, dados pluviométricos e parâmetros hidráulicos do solo. Esses dados estão organizados em três conjuntos, geral, solo e atmosfera, sendo os dois últimos referentes às condições iniciais e de contorno. A Figura 3 apresenta um esquema de agrupamento dos dados de entrada necessários para a simulação da dinâmica da água no solo dos telhados verdes com o Hydrus-1D.

Tabela 1 - Parâmetros hidráulicos do solo dos telhados verdes instalados em Caruaru, Pernambuco, em 2009

\begin{tabular}{c|c|c|c|c|c}
\hline Telhado & $\boldsymbol{\Theta}_{\mathbf{r}}\left(\mathbf{m}^{\mathbf{3}} / \mathbf{m}^{\mathbf{3}}\right)$ & $\boldsymbol{\Theta}_{\mathbf{s}}\left(\mathbf{m}^{\mathbf{3}} / \mathbf{m}^{\mathbf{3}}\right)$ & $\boldsymbol{\alpha}$ & $\mathbf{n}$ & $\mathbf{K}_{\mathbf{s}}(\mathbf{m} / \mathbf{h})$ \\
\hline Grama & 0,0386 & 0,387 & 0,0424 & 1,7049 & 0,0696458 \\
Cacto & 0,0381 & 0,384 & 0,0414 & 1,7165 & 0,0698681 \\
\hline
\end{tabular}

Nota: Legenda:

$\theta$ r e $\theta$ s: umidades volumétricas residual e saturada $\left[\mathrm{L}^{3} \mathrm{~L}^{-3}\right]$;

$\mathrm{K}_{\mathrm{s}}$ : condutividade hidráulica saturada do solo $\left[\mathrm{LT}^{-1}\right]$, e parâmetros adimensionais de forma $\alpha$ e $\mathrm{n}$

Tabela 2 - Frações granulométricas dos solos dos telhados verdes instalados em Caruaru, Pernambuco, em 2009

\begin{tabular}{c|c|c|c|c|c}
\hline Telhado & Argila (\%) & Areia (\%) & Silte (\%) & $\boldsymbol{\rho}\left(\mathbf{g} / \mathbf{c m}^{\mathbf{3}}\right)$ & Matéria orgânica (\%) \\
\hline Grama & 5,70 & 80,07 & 14,23 & 1,35 & 14,9 \\
Cacto & 5,69 & 80,01 & 14,30 & 1,32 & 12,7 \\
\hline
\end{tabular}

166 Santos, P. T. da S.; Santos, S. M. dos; Montenegro, S. M. G. L.; Coutinho, A. P.; Moura, G. S. S. de; Antonino, A. C. D. 


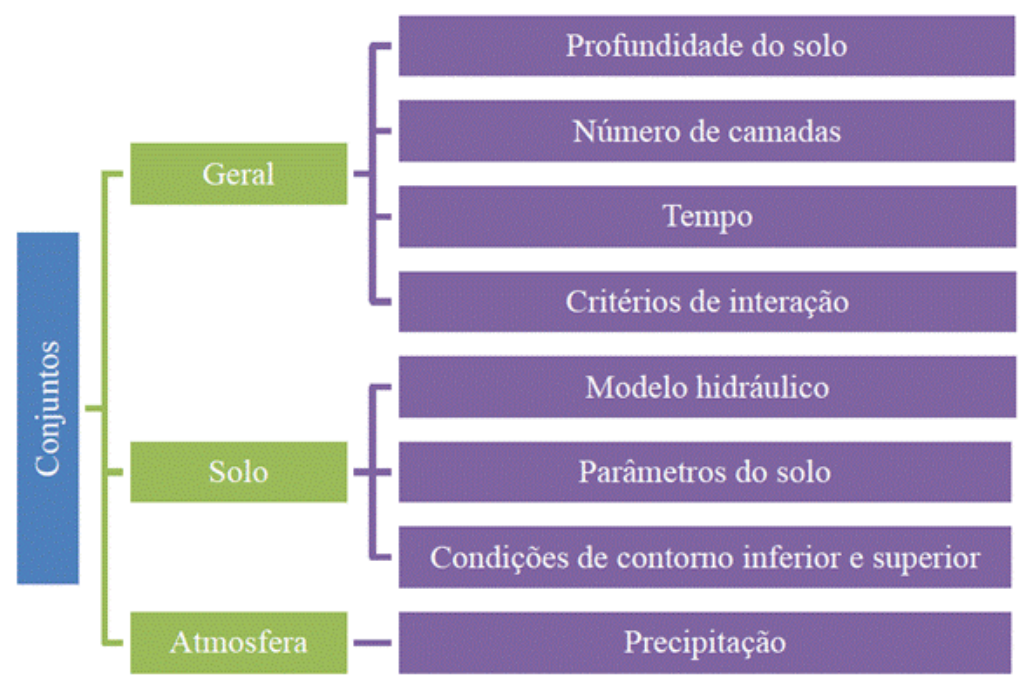

Figura 3 - Esquema de agrupamento dos dados de entrada do Hydrus-1D

Na simulação com o Hydrus-1D foi considerado o tempo total de $30 \mathrm{~min}$, discretizado em intervalos de $1 \mathrm{~min}$. O solo de profundidade de $3 \mathrm{~cm}$ foi espacialmente caracterizado em intervalos equidistantes de $0,3 \mathrm{~cm}(\Delta \mathrm{z})$, sendo usados os resultados obtidos com a granulometria do solo. $\mathrm{O}$ Hydrus-1D possui em sua interface um complemento chamado Rosetta Lite v3.1, que estima os parâmetros hidráulicos do solo utilizando as frações granulométricas e densidade das partículas, por meio de funções de pedotransferência. Os resultados obtidos pelo Rosetta Lite v3.1 foram ajustados a partir dos resultados dos testes de infiltração.

As condições de contorno foram determinadas do experimento, sendo a condição de contorno superior determinada como atmosférica, composta da precipitação pluviométrica e do potencial crítico do ar na superfície, assumido ser de $12.000 \mathrm{kPa}$ $\left(120.000 \mathrm{~cm}\right.$ de $\left.\mathrm{H}_{2} \mathrm{O}\right)$, que corresponde aproximadamente ao valor da sucção de um solo seco ao ar (ANTONINO, 1988). A condição de contorno inferior adotada para o modelo foi a de fluxo variável, devido às camadas de solo que compõem o substrato dos telhados verdes (HILTEN; LAWRENCE; TOLLNER, 2008). Nessa condição o modelo calcula o fluxo gerado na base do perfil, que resulta no escoamento superficial (Figura 4).

As condições iniciais do solo para a modelagem são as mesmas do início da simulação da chuva, sendo utilizados os seguintes valores para as umidades volumétricas: $0,0402 \mathrm{~m}^{3} / \mathrm{m}^{3}$ para o telhado de grama; e $0,0398 \mathrm{~m}^{3} / \mathrm{m}^{3}$ para o telhado de cacto, obtidas com o emprego das sondas TDR instaladas.

\section{Validação do modelo}

Para validar os parâmetros adotados, foram utilizadas as seguintes variáveis estatísticas: coeficiente de determinação, razão de desvios, coeficiente de massa residual e erro padrão, que estão descritos a seguir.

O coeficiente de determinação (R2) indica a proporção da variância nos valores calculados no modelo, que podem ser atribuídos aos observados (WILLMOTT et al., 1985), variando entre 0 (zero) e 1 (um), conforme a Equação 2. Quanto mais próximo da unidade for esse coeficiente, maior será a validade da regressão.

$R^{2}=\frac{[n \cdot(\Sigma M i \cdot T i)-\Sigma M i \cdot \Sigma T i]^{2}}{n \cdot\left[\Sigma T i^{2}-(\Sigma T i)^{2}\right]\left[n \cdot \Sigma M i^{2}-(\Sigma M i)^{2}\right]}$

Eq. 2

Sendo:

$M_{i}$ corresponde aos valores calculados pelo modelo;

$T_{i}$ os valores observados nos experimentos, e

$n$ a quantidade de valores obtidos no experimento e no modelo.

A razão de desvios (RD) (Equação 3) descreve a razão entre a dispersão dos valores observados e os calculados pelo modelo, e tende a 1 (um) quando há igualdade entre os valores observados e calculados (WILLMOTT et al., 1985).

$R D=\frac{\Sigma(M i-\bar{M})^{2}}{\Sigma(T i-\bar{M})^{2}}$

Sendo:

$\bar{M}$ corresponde à média dos valores calculados. 
O coeficiente de massa residual (CMR) indica se o modelo tende a superestimar $(\mathrm{CMR}<0)$ ou subestimar $(\mathrm{CMR}>0)$ os valores determinados experimentalmente. $\mathrm{Na}$ ausência de desvios sistemáticos entre os valores observados e calculados, o valor esperado tende a zero (WILLMOTT et al., 1985) (Equação 4).

$C R M=\left(\frac{\Sigma M i-\Sigma T i}{\Sigma M i}\right)$

Eq. 4

Segundo Willmott et al. (1985), os valores ótimos de CMR e RD são 0 (zero) e 1 (um) respectivamente. $\mathrm{O}$ erro padrão $(\mathrm{EP})$ corresponde à diferença entre o valor de cada amostra e a média dos valores experimentais (Equação 5).

$E P=\sqrt{\frac{\sum_{i=1}^{n}(T i-\bar{T})^{2}}{n}}$

Eq. 5
Sendo:

$\bar{T}$ corresponde à média dos valores experimentais.

\section{Resultados e discussão}

\section{Resultados experimentais}

\section{Hidrogramas}

Os resultados obtidos durante os experimentos de simulação de chuva com precipitações de intensidades diferentes - experimento 1 de 42 $\mathrm{mm} / \mathrm{h}$ (Figura $5 \mathrm{a}$ ) e experimento 2 de $79 \mathrm{~mm} / \mathrm{h}$ (Figura 5b) - mostram um comportamento do escoamento superficial semelhante nos dois telhados verdes.

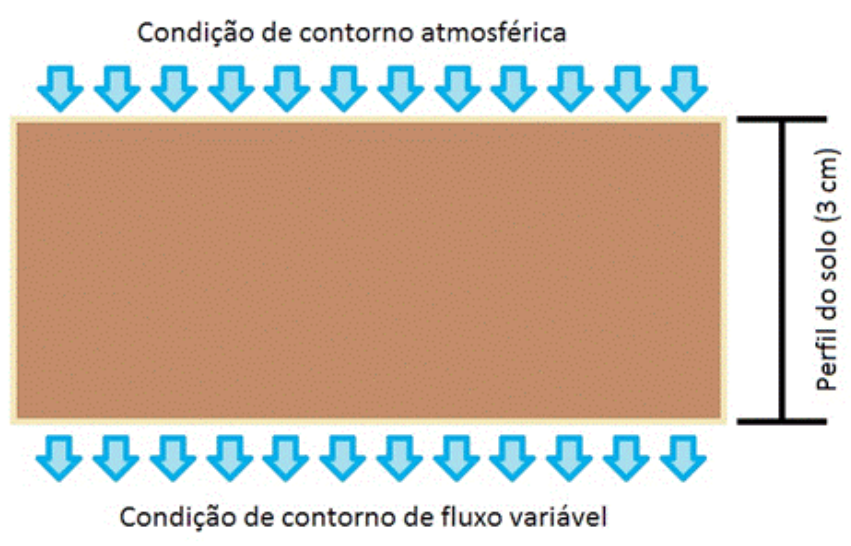

Figura 4 - Condições de contorno adotadas no modelo Hydrus-1D

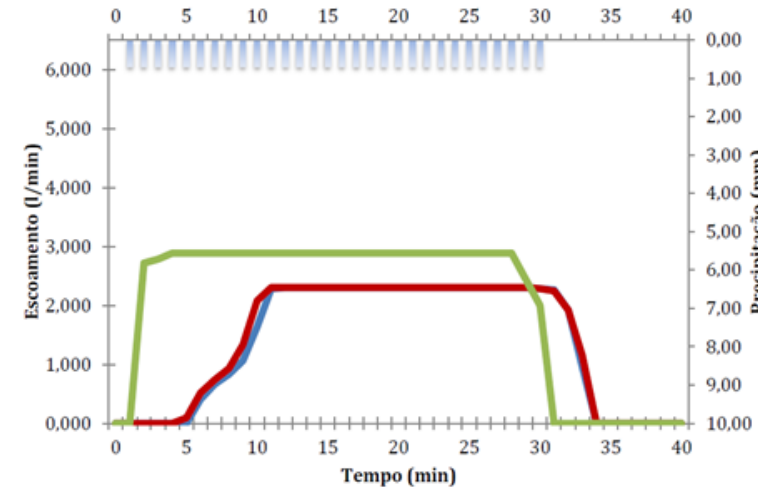

(a) Precipitação com i $=42 \mathrm{~mm} / \mathrm{h}$

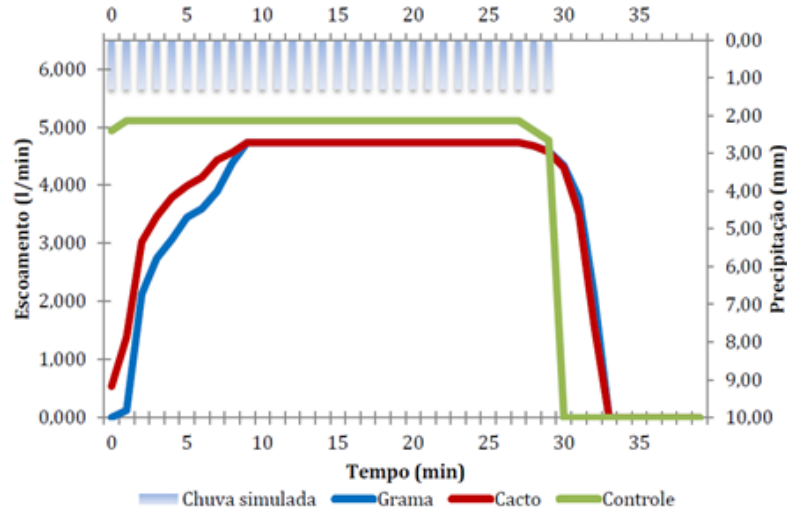

(b) Precipitação com i $=79 \mathrm{~mm} / \mathrm{h}$

Figura 5 - Escoamento dos telhados verdes (cacto Melocactus macrodiscus e grama Cynodium dactylum) com precipitações de intensidades distintas, com o modelo Hydrus-1D

168 Santos, P. T. da S.; Santos, S. M. dos; Montenegro, S. M. G. L.; Coutinho, A. P.; Moura, G. S. S. de; Antonino, A. C. D. 
No que se refere ao retardo no início do escoamento superficial da água precipitada, os resultados obtidos no experimento 1 (Figura 5a) mostram claramente que o início do ramo ascendente dos hidrogramas de ambos os telhados verdes está deslocado em relação ao início do ramo ascendente do hidrograma do telhado controle, em 5 min para o telhado com cacto e em 6 min para o telhado com grama. Esse comportamento de retardo no início do escoamento por conta da existência dos telhados verdes também foi observado por Liesecke (1998), VanWoert et al. (2005), Mentes, Raes e Hermy (2006), BursztaAdamiak (2012) e outros. Com o aumento da intensidade da precipitação, experimento 2 (Figura 5b), observou-se o mesmo comportamento de retardo de ambos os telhados vegetados com relação ao telhado convencional, do experimento 1, de forma mais discreta. Tal fato pode ter ocorrido pela saturação imediata dos vazios do substrato por conta do aumento da intensidade precipitada.

Com relação ao tempo para ocorrência do pico do escoamento superficial, efeito detenção, verificouse nos dois experimentos o atraso na ocorrência destes com relação ao pico do escoamento superficial da água escoada do telhado controle. No experimento $1 \mathrm{o}$ atraso foi da ordem de $11 \mathrm{~min}$ em ambos os telhados, e no experimento 2 foi de 10 min para o telhado com cacto e de 11 min para o telhado com grama. Esses resultados assemelham-se aos obtidos por Palla et al. (2008), que observaram valores entre 7 min e 15 min para intensidades de precipitação semelhantes, em um experimento realizado em Genova, Itália, utilizando telhados verdes com vegetação de grama.

No que se refere à redução no pico do hidrograma do escoamento superficial, efeito retenção, verificou-se que no experimento com menor intensidade de água precipitada, experimento 1 , a diferença entre os volumes escoados para os tonéis oriundos dos telhados vegetados foi maior que no experimento com maior intensidade de água precipitada. Assim como em Carter e Rasmussen (2006), aqui também foi observado tanto que os picos de escoamento para a precipitação menor foram muito menores nos telhados verdes que no telhado convencional, quanto que esse efeito foi muito reduzido para a precipitação maior. Os telhados vegetados apresentaram mesma magnitude no pico do hidrograma do escoamento em cada experimento, não tendo sido detectada, portanto, interferência do tipo de vegetação sobre o desempenho dos telhados verdes. O estado de envelhecimento da grama, bastante acentuado, pode ter contribuído para que o efeito retenção não tenha sido maior neste caso que no telhado com cacto, como era de se esperar, uma vez que normalmente, devido à morfologia inerente à planta, essa vegetação apresenta maior densidade de folhas.

Com relação ao ramo descendente do hidrograma, em ambos os experimentos, os telhados vegetados apresentaram um tempo de escoamento maior que o telhado controle, bem como um retardo no início do ramo descendente, como observado também por Costa, Costa e Poleto (2012). A presença de uma grande fração de areia no solo (Tabela 2) sugere que este apresenta maior porosidade em seu perfil, o que influi diretamente no tempo necessário para que ele atinja o estado de saturação (ramos ascendentes dos hidrogramas dos telhados verdes), e para que o escoamento também ocorra de forma mais rápida (ramos descendentes dos mesmos hidrogramas) (Figuras 5a e 5b). Além disso, como a areia possui maior condutividade hidráulica em relação à argila ou ao silte, o perfil do solo pode drenar mais facilmente a água armazenada em sua camada.

\section{Volume escoado}

O balanço de entrada (volume precipitado) e saída de água (volume escoado), bem como o volume retido na estrutura ao final da simulação de chuva, cessados os escoamentos provenientes dos telhados, para os experimentos 1 e 2, estão, respectivamente, apresentados nas Tabelas 3 e 4 .

Tabela 3 - Balanço de entrada e saída de água do sistema no experimento 1 ( $\mathrm{i}=\mathbf{4 2} \mathrm{mm} / \mathrm{h}$ ) dos telhados verdes instalados em Caruaru, Pernambuco, em 2009

\begin{tabular}{ccccc}
\hline Telhado & Precipitação $(\mathbf{L})$ & Volume escoado $(\mathbf{L})$ & Volume retido (L) & \% Retido \\
\hline Grama & 84,00 & 55,793 & 28,207 & 33,6 \\
Cacto & 84,00 & 57,074 & 26,926 & 32,1 \\
Controle & 84,00 & 82,095 & 1,905 & 2,3 \\
\hline
\end{tabular}


Tabela 4 - Balanço de entrada e saída de água do sistema no experimento $2(\mathbf{i}=79 \mathrm{~mm} / \mathrm{h})$ dos telhados verdes instalados em Caruaru, Pernambuco, em 2009

\begin{tabular}{ccccc}
\hline Telhado & Precipitação (L) & Volume escoado (L) & Volume retido (L) & \% Retido \\
\hline Grama & 157,2 & 132,879 & 24,321 & 15,5 \\
Cacto & 157,2 & 137,973 & 23,227 & 14,2 \\
Controle & 157,2 & 152,678 & 4,522 & 2,1 \\
\hline
\end{tabular}

Como era de se esperar, os telhados verdes apresentaram capacidade de retenção do volume total precipitado superior ao telhado controle em ambos os experimentos, sendo os valores obtidos com a precipitação de menor intensidade, experimento 1 , superiores aos valores obtidos com a maior intensidade, experimento 2. Enquanto, para a precipitação de intensidade igual a 42 $\mathrm{mm} / \mathrm{h}$, a retenção dos telhados verdes foi da ordem de $30 \%$ (33,6\% para o telhado com grama e $32,1 \%$ para o telhado com cacto), no caso da intensidade igual a $79 \mathrm{~mm} / \mathrm{h}$, os valores foram da ordem de $15 \%$ (15,5\% para o telhado com grama e $14,2 \%$ para o telhado com cacto). Carter e Rasmussen (2006) e Burszta-Adamiak (2012) também observaram essa relação inversa entre o volume precipitado e o percentual de chuva retido.

O telhado controle manteve uma capacidade de retenção praticamente inalterada $(2,3 \%$ para a intensidade de $42 \mathrm{~mm} / \mathrm{h}$ e $2,1 \%$ para a intensidade de $79 \mathrm{~mm} / \mathrm{h}$ ), e dentro dos padrões estudados na literatura, em torno de $1,7 \%$ a $2,5 \%$ (LAAR, 2001). O mesmo autor cita que o estado das telhas, a presença de musgos, líquens e poeira entre elas, assim como a inclinação do telhado contribuem para a retenção do escoamento em telhados comuns.

Burszta-Adamiak (2012) relacionou o aumento na retenção dos telhados verdes com relação ao telhado convencional principalmente com a estrutura de cada um deles, ou seja, os telhados vegetados retêm parte da água na camada do substrato e nas camadas estruturais (na maior parte, na camada de drenagem, que compreende um meio poroso ou elementos plásticos de drenagem), até mesmo durante eventos chuvosos de maior intensidade, e uma parte da água evapora para a atmosfera. Nesse contexto, segundo o autor, apenas o excesso escoa da estrutura de várias camadas do telhado verde.

Por outro lado, no caso do telhado convencional, Burszta-Adamiak (2012) explica que, após a superfície ser inicialmente molhada, uma quantidade muito pequena de chuva é retida nas irregularidades do material de construção e apenas em temperaturas do ar suficientemente elevadas um pouco da água evapora, de forma que o volume de água remanescente seja descarregado rapidamente na forma de escoamento superficial.

\section{Resultados simulados no Hydrus-1D}

Os resultados dos ensaios de infiltração, da granulometria e do experimento de simulação de chuva subsidiaram as informações que foram inseridas como dados de entrada para a simulação numérica dos telhados verdes, com o software Hydrus-1D. Além das características físicas do experimento, o modelo se assemelha à realidade em escala de tempo, de modo que o intervalo de tempo adotado para as simulações seja igual ao do experimento.

\section{Resultados da simulação do telhado verde com cacto}

A Figura 6 mostra os escoamentos observados nos experimentos 1 (Figura 6a) e 2 (Figura 6b) de simulação de chuva, e o simulado pelo Hydrus-1D para o telhado verde com vegetação de cacto.

Ao se analisarem os resultados obtidos do telhado verde de cacto com a precipitação de $42 \mathrm{~mm} / \mathrm{h}$ (Figura 6a), pode-se observar que no ramo ascendente do hidrograma, no período de 0 a 11 min, e no ramo descendente do hidrograma, de 30 min a 40 min, o Hydrus-1D superestima alguns valores do escoamento superficial, sugerindo alguma dificuldade do programa em ajustar os valores de escoamento em solo não saturado. Entre $11 \mathrm{~min}$ e $30 \mathrm{~min}$, quando ocorre saturação da camada de solo, praticamente não existe diferença entre os valores observados e os simulados. Esse desempenho do programa Hydrus-1D pode ser justificado pelo fato de o programa utilizar dados de umidade do solo da saída de um intervalo de tempo como dados de entrada para o próximo intervalo de tempo. Por outro lado, quando o perfil do solo se torna saturado e os valores de umidade se tornam constantes, o programa realiza perfeitamente as interações necessárias para simular o escoamento, uma vez que não há diferença nos valores de umidade como entrada nos intervalos de tempo seguintes.

170 Santos, P. T. da S.; Santos, S. M. dos; Montenegro, S. M. G. L.; Coutinho, A. P.; Moura, G. S. S. de; Antonino, A. C. D. 


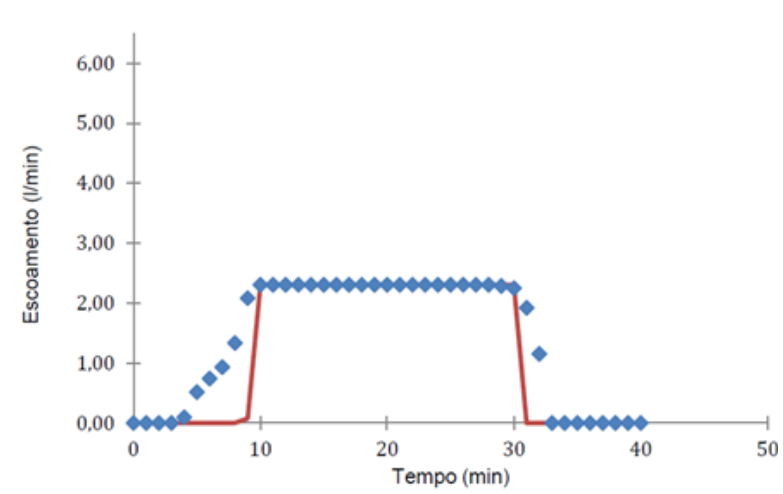

(a) Precipitação com i $=42 \mathrm{~mm} / \mathrm{h}$

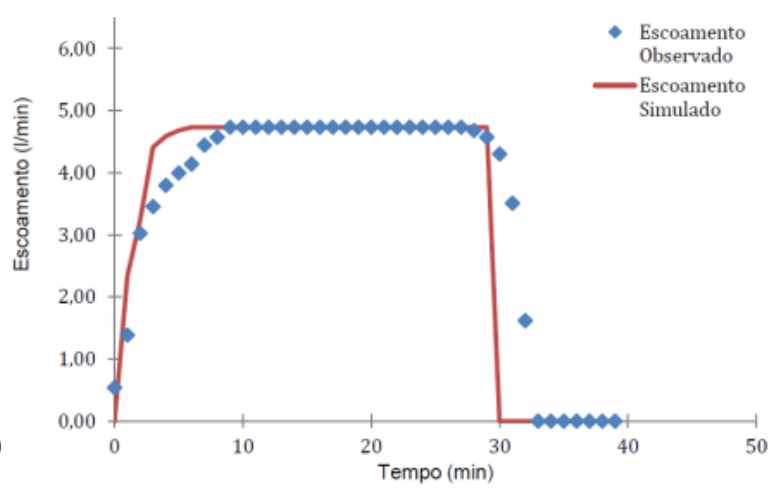

(b) Precipitação com i $=79 \mathrm{~mm} / \mathrm{h}$

Figura 6 - Escoamentos observados e simulados no telhado verde com cacto Melocactus macrodiscus para precipitações de intensidades distintas, com o modelo Hydrus-1D

No caso da precipitação de $79 \mathrm{~mm} / \mathrm{h}$ (Figura 6b), pode-se observar que houve um melhor ajuste entre os escoamentos observados e os simulados na ascensão e na região do pico do hidrograma, sendo que em todo este trecho apenas no intervalo de 3 min a 7 min o escoamento observado apresenta-se abaixo do escoamento simulado; por outro lado, o ramo descendente do hidrograma não é bem representado pelo modelo. Como a vegetação cacto não proporciona uma completa cobertura do solo, o mesmo fica exposto à precipitação, que em grande intensidade satura rapidamente o solo do telhado verde. Nesse contexto, o hidrograma apresentado na Figura $6 \mathrm{~b}$ sugere uma maior facilidade do programa Hydrus1D em simular o escoamento no perfil, entrando em saturação mais rapidamente.

\section{Resultados da simulação do telhado verde com grama}

Em relação à simulação do escoamento do telhado verde de grama, a Figura 7 mostra os hidrogramas observados nos experimentos 1 (Figura 7a) e 2 (Figura 7b), e simulados pelo Hydrus-1D.

Assim como ocorreu com a vegetação cacto, para a precipitação com intensidade de $42 \mathrm{~mm} / \mathrm{h}$, observou-se a mesma dificuldade para o ajuste do ramo ascendente e descendente do hidrograma do telhado verde de grama com a precipitação de mesma intensidade (Figura 7a).

A Figura $7 b$ ilustra o escoamento observado e o escoamento simulado pelo Hydrus-1D para o telhado verde com vegetação de grama para uma intensidade de precipitação de $79 \mathrm{~mm} / \mathrm{h}$. Da mesma forma que nos casos anteriores, aqui também o escoamento simulado pelo Hydrus-1D reproduz bem o formato do hidrograma observado, e não ocorreu diferença na estimativa dos valores da vazão de pico.

\section{Validação do modelo}

Os valores dos parâmetros de validação do modelo para os resultados obtidos com ambos os telhados vegetados estão apresentados na Tabela 5.

Considerando-se que, quanto mais próximo da unidade for o coeficiente de determinação $\left(R^{2}\right)$, maior será a validade da regressão, verifica-se pelos valores deste coeficiente que as melhores regressões foram obtidas com a simulação da chuva de maior intensidade em ambos os telhados vegetados, tendo sido, neste caso, de 0,95 para o telhado com grama e de 0,92 para o telhado com cacto, enquanto para a chuva de menor intensidade esse coeficiente não atingiu o valor de 0,80 para ambos os telhados verdes $(0,74$ para o telhado com grama e 0,77 para o telhado com cacto).

No que se refere ao erro padrão (EP), da simulação do telhado com cacto para a chuva de maior intensidade resultou a maior diferença, da ordem de 0,15 entre o valor de cada amostra e a média dos valores experimentais. Os demais valores obtidos para o erro padrão foram próximos e bem inferiores $(0,029$ para o telhado com grama e 0,027 para o telhado com cacto, ambos referentes à chuva de menor intensidade, e 0,025 para o telhado com grama, referente à chuva de maior intensidade) ao obtido para a chuva de maior intensidade com o telhado com cacto. 


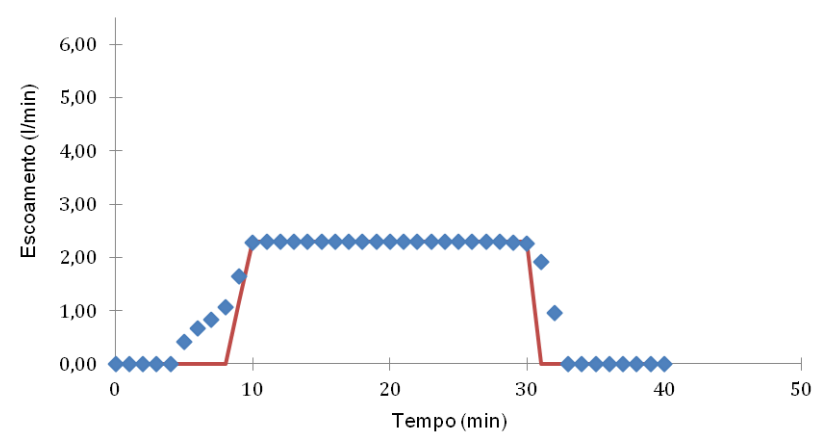

(a) Precipitação com i $=42 \mathrm{~mm} / \mathrm{h}$

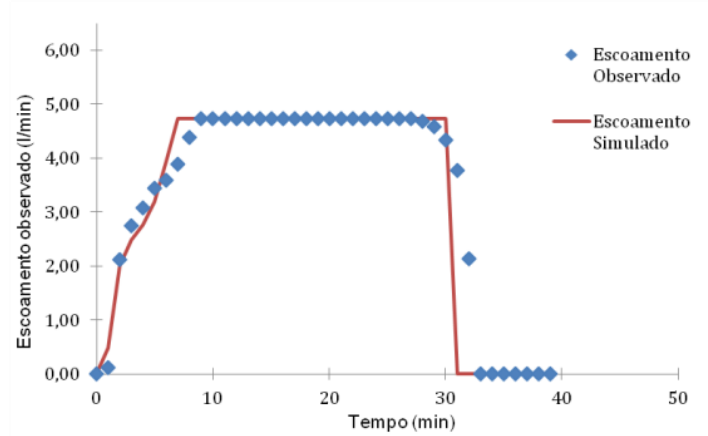

(b) Precipitação com i $=79 \mathrm{~mm} / \mathrm{h}$

Figura 7 - Escoamentos observados e simulados no telhado verde com grama Cynodium dactylum para precipitações de intensidades distintas, com o modelo Hydrus-1D

Tabela 5 - Índices estatísticos de validação do modelo dos telhados verdes instalados em Caruaru, Pernambuco, em 2009

\begin{tabular}{ccccc}
\hline \multicolumn{5}{c}{$\mathbf{i}=\mathbf{4 2} \mathbf{~ m m} / \mathbf{h}$} \\
\hline Telhado & $\mathbf{R}^{\mathbf{2}}$ & $\mathbf{E P}$ & $\mathbf{C R M}$ & $\mathbf{R D}$ \\
\hline Grama & 0,74 & 0,029 & $-1,72 \mathrm{E}-01$ & 1,016 \\
Cacto & 0,77 & 0,028 & $-1,78 \mathrm{E}-01$ & 1,067 \\
\hline \multicolumn{5}{c}{$\mathbf{i}=\mathbf{7 9} \mathbf{~ m m} / \mathbf{h}$} \\
Grama & 0,95 & 0,025 & $-1,12 \mathrm{E}-01$ & 0,758 \\
Cacto & 0,92 & 0,153 & $-2,71 \mathrm{E}-02$ & 1,079 \\
\hline
\end{tabular}

Nota: Legenda:

$$
\begin{aligned}
& \mathrm{R}^{2}=\text { coeficiente de determinação; } \\
& \mathrm{EP} \text { = erro padrão; } \\
& \mathrm{CRM}=\text { coeficiente de massa residual; e } \\
& \mathrm{RD} \text { = razão de desvios. }
\end{aligned}
$$

Em todos os resultados obtidos, observou-se que, em geral, o modelo superestimou os valores determinados experimentalmente, uma vez que o coeficiente de massa residual foi negativo em todos os casos $(\mathrm{CMR}<0)$ : $-0,172$ para o telhado com grama e $-0,178$ para o telhado com cacto referente à chuva de menor intensidade; $-0,112$ para o telhado com grama e $-0,027$ para o telhado com cacto referente à chuva de maior intensidade. Considerando que o valor ótimo de CMR é 0 (zero) (WILLMOTT et al., 1985), os melhores resultados foram obtidos para o telhado com cacto quando foi simulado o evento de maior intensidade, uma vez que, neste caso, o CRM se apresentou 2,7\% distante de seu valor ótimo (0).

Com relação à dispersão entre os valores observados e os valores calculados, todos os valores da razão de desvios (RD) foram próximos a 1 (um): 1,01 para o telhado com grama e 1,06 para o telhado com cacto referente à chuva de menor intensidade; 0,75 para o telhado com grama e 1,07 para o telhado com cacto referente à chuva de maior intensidade. Considerando que este índice tende a 1 (um) quando há igualdade entre os valores observados e calculados, os resultados que se mostraram mais diferentes foram os do telhado com grama quando foi simulado o evento de maior intensidade.

\section{Conclusões}

O emprego dessa técnica exige o estabelecimento de parâmetros construtivos (como altura da mureta de delimitação da área e limitação do subtrato e vegetação, impermeabilização, altura de substrato necessária, entre outros) que representem o adequado desempenho da estrutura diante das condições climatológicas locais.

Os resultados apresentados ratificam que os fatores que mais influenciam o funcionamento desse tipo de equipamento são os tipos de vegetação e solo utilizados, assim como a espessura dessas camadas.

Como era de se esperar, os telhados verdes apresentaram capacidade de retenção do volume total precipitado superior ao telhado controle em ambos os experimentos, com coberturas diferentes, sendo os valores obtidos com a precipitação de menor intensidade, experimento 1 , superiores aos

172 Santos, P. T. da S.; Santos, S. M. dos; Montenegro, S. M. G. L.; Coutinho, A. P.; Moura, G. S. S. de; Antonino, A. C. D. 
valores obtidos com a maior intensidade, experimento 2 .

O modelo Hydrus-1D representou bem a realidade do experimento, e alguns fatores podem ter influenciado positivamente para o bom ajuste do modelo:

(a) uso da umidade inicial dos solos como dado de entrada do modelo;

(b) discretização temporal em segundos, como considerado no experimento;

(c) caracterização hidráulica do solo pela metodologia Beerkan; e

(d) uso do software Rosetta Lite v3.1.

Atribui-se a não concordância dos valores simulados e observados, quando ocorreram, à interceptação pela cobertura vegetal verificada no experimento, que não é considerado na simulação com o modelo Hydrus-1D.

O modelo Hydrus-1D se mostrou mais eficiente no cálculo do fluxo da água em perfis de solo saturados, uma vez que os valores desta componente se tornam constantes após a saturação do perfil do solo.

A qualidade do ajuste do modelo Hydrus-1D para a intensidade de $42 \mathrm{~mm} / \mathrm{h}$ pode ter sido influenciada pela interceptação vegetal, resultando no distanciamento entre os valores observados e simulados, no ramo ascendente do hidrograma.

\section{Referências}

ANTONINO, A. C. D. Simulação Numérica do Comportamento da Água no Solo. Recife, 1988. 118 f. (Mestrado em Tecnologias Energéticas Nucleares) - Departamento de Energia Nuclear, Universidade Federal de Pernambuco, Recife, 1988.

ASSOCIAÇÃO BRASILEIRA DE NORMAS TÉCNICAS NBR 7181: solo: análise granulométrica. Rio de Janeiro, 1984. 13 p.

BURSZTA-ADAMIAK, E. Analysis of the Retention Capacity of Green Roofs. Journal of Water and Land Development, v. 16, n. 1/6, p. 3-9, 2012.

CARTER, T. L.; RASMUSSEN, T.C. Hydrologic Behavior of Vegetated Roofs. Journal of the American Water Resources Association, v. 42, n. 5, p.1261-1274, 2006.

COSTA, J.; COSTA, A.; POLETO, C. Telhado Verde: redução e retardo do escoamento superficial. Revista de Estudos Ambientais, v. 14, n. 2, edição especial, p. 50-56, 2012.
COUTINHO, A. P. et al. Determinação de Equações de Chuvas Intensas para Municípios das Mesorregiões do Estado de Pernambuco Com Dados Pluviométricos. In: SIMPÓSIO DE RECURSOS HÍDRICOS DO NORDESTE, 10., Fortaleza, 2010. Anais... Fortaleza, 2010. 14 p.

DUNNETT N. P.; KINGSBURY, N. Planting Green Roofs and Living Walls. Portland (OR): Timber Press, 2004.

GETTER, K. L.; ROWE, D. B. The Role of Extensive Green Roofs in Sustainable Development. Hortscience, v. 41, n. 5, p.12761285, 2006.

HILTEN, R. N.; LAWRENCE, T. M.; TOLLNER, E. W. Modeling Stormwater Runoff From Green Roofs With HYDRUS-1D. Journal of Hydrology, v. 358, n. 3/4, p. 288-293, 2008.

HORNER, W. W.; JENS, S. W. Surface Runoff Determination From Rainfall Without Using Coefficients. Transactions of the ASAE, v. 107, p. 1039-1117, 1942.

INSTITUTO BRASILEIRO DE GEOGRAFIA E ESTATÍSTICA. Censo de 2010. Disponível em: <http://www.ibge.gov.br/home/presidencia/noticia s/noticia_visualiza.php?id_noticia $=1766>$. Acesso em: 28 dez. 2012.

LAAR, M. Estudo de Aplicação de Plantas em Telhados Vivos Extensivos em Cidades de Clima Tropical. In: ENCONTRO NACIONAL DE CONFORTO NO AMBIENTE CONSTRUÍDOENCAC, 6., São Pedro, 2001. Anais... São Pedro: ANTAC, 2001. 1 CD-ROM.

LIESECKE, H. The Retention Capacity of Green Roofs. German Horticulture, v. 47, p. 46-53, 1998.

MENTES, J.; RAES, D.; HERMY, M. Green Roofs as a Tool For Solving the Rainwater Runoff Problem in the Urbanized 21st Century? Landscape and Urban Planning, v. 77, n. 3, p. 217-226, 2006.

PALLA, A. et al. Modelling Storm Water Control Operated by Green Roofs at the Urban Catchment Scale University of Genoa - Italy, In:

INTERNATIONAL CONFERENCE ON URBAN DRAINAGE, 11., Edinburgh, 2008.

Proceedings... Edinburgh, 2008.

PECK, S. W. Greenbacks From Green Roofs: forging a new industry in Canada. Peck and associates, Canadian Mortgage and Housing Corporation Research Report, 1999. 
REICHARDT, K. A Água em Sistemas

Agrícolas. São Paulo: Manole, 1990.

SANTOS, S. et al. Determinação da Utilidade do Uso de Telhado Verde no Agreste Pernambucano. In: ENCONTRO NACIONAL, 5.; ENCONTRO LATINO-AMERICANO SOBRE EDIFICAÇÕES E COMUNIDADES SUSTENTÁVEIS, 3., Recife, 2009. Anais... Recife, 2009. 10 p.

SANTOS, T.E.M.; MONTENEGRO, A. A. A. Erosividade e Padrões Hidrológicos de Precipitação no Agreste Central Pernambucano. Revista Brasileira de Engenharia Agrícola e Ambiental, v. 16, n. 8, p. 871-880, 2012.

SOUZA, E. S. et al. Caracterização Hidrodinâmica de Solos: aplicação do método Beerkan. Revista Brasileira de Engenharia Agrícola e Ambiental, v. 12, n. 2, p.128-135, 2008.
UNITED NATIONS. World Urbanization

Prospects: the 2005 revision. Working Paper No ESA/P/WP/2005. Department of economic and Social Affairs - Population Division., 2005.

Disponível em:

<http://www.un.org/esa/population/publications/W UP2005/2005wup.htm>. Acesso em: 14 mar. 2012.

VANWOERT, N. et al. Green Roof Stormwater Retention: effects of roof surface, slope and media depth. Journal of Environmental Quality, v. 34, n. 3, p. 1036-1044, 2005.

WILLMOTT, C. J. et al. Statistics For the Evaluation and Comparison of Models. Journal of Geophysical Research, v. 90, n. C5, p. 89959005, 1985.

\section{Agradecimentos}

Os autores agradecem à Facepe, pela bolsa de mestrado concedida ao primeiro autor, e ao CNPq, pelo apoio financeiro na realização do projeto e bolsa de mestrado do terceiro autor.

\section{Revista Ambiente Construído}

Associação Nacional de Tecnologia do Ambiente Construído

Av. Osvaldo Aranha, $99-3^{\circ}$ andar, Centro

Porto Alegre - RS - Brasil

CEP 90035-190

Telefone: +55 (51) 3308-4084

Fax: +55 (51) 3308-4054

www.seer.ufrgs.br/ambienteconstruido

E-mail: ambienteconstruido@ufrgs.br

174 Santos, P. T. da S.; Santos, S. M. dos; Montenegro, S. M. G. L.; Coutinho, A. P.; Moura, G. S. S. de; Antonino, A. C. D. 